\title{
Influence of Filler Structure on Microhardness of Carbon Black-Polymer Composites
}

\author{
A. Flores, M. E. CAGiaO, T. A. EZQUerRA, F. J. BALtÁ CAllejA \\ Instituto de Estructura de la Materia, C.S.I.C., Serrano 119, 28006 Madrid, Spain
}

Received 21 February 2000; accepted 24 April 2000

\begin{abstract}
The microhardness, $H$, of carbon black-polycarbonate and carbon blacklow-density polyethylene composites was investigated. Two types of microadditives with different average particle sizes were employed. It has been shown that the morphology of the polymeric matrix conspicuously influences the hardness dependence of the composites with volume concentration of filler, $\phi$. The microhardness of the carbon black-polycarbonate composites shows a steplike behavior with respect to carbon black content, while the $H$ value of the carbon black-low-density polyethylene composite linearly increases with increasing $\phi$. The influence of filler structure on the microhardness of the carbon black-polymer composites is also discussed. Results favor the concept that a smaller carbon black particle size (smaller aggregate diameters and interaggregate distances) enhances the microhardness of the composites. (C) $2000 \mathrm{John}$ Wiley \& Sons, Inc. J Appl Polym Sci 79: 90-95, 2001
\end{abstract}

Key words: carbon black; polycarbonate; LDPE; percolation; microhardness

\section{INTRODUCTION}

The method currently used to increase the electrical conductivity of common insulating polymers is to fill them with conductive powders. ${ }^{1} \mathrm{~A}$ transition from insulating to noninsulating behavior is observed when the volume concentration of conductive filler reaches a critical value, $\phi_{c}$ (percolation threshold). Among all the classes of microadditive-polymer materials, carbon blackpolymer composites are of special interest because of relatively high conductivity values obtained at low carbon black concentrations. ${ }^{2,3}$ Compression-molded carbon black-polycarbonate (PC) and low-density polyethylene (LDPE) composites show conductivity values within the range $10^{-5}-1 \Omega^{-1} \mathrm{~cm}^{-1}$ above $\phi_{c}\left(\phi_{c}=1 \%-10 \%\right) .^{2,3}$

Correspondence to: F. J. Baltá Calleja.

Contract grant sponsor: DGICYT; grant number: PB94-0049.

Journal of Applied Polymer Science, Vol. 79, 90-95 (2001)

(C) 2000 John Wiley \& Sons, Inc.
The influence of the carbon black structure on the percolation threshold of these composites has been investigated. ${ }^{2,3}$ The electrical conductivity of injection-molded carbon-black-filled high-density polyethylene has also been studied. ${ }^{4,5}$ In particular, the influence of the matrix molecular weight on the conductivity values and on the percolation threshold of the composites was highlighted. ${ }^{5}$

A broad utilization of carbon-filled polymers as conductive polymeric materials often requires not only high electrical conductivity values but also an appropriate range of mechanical properties. ${ }^{6}$ Microindentation hardness has emerged in recent years as a new method for the evaluation of the mechanical properties of polymers and polymer composites. ${ }^{7-10}$ On the one hand, it is well known that microhardness is correlated to the morphology of the polymeric material. ${ }^{11,12}$ On the other hand, $H$ is related to macroscopic mechanical properties such as yield stress and Young's modulus. ${ }^{13,14}$ We have examined the influence of the additive on the mechanical properties of carbon- 
Table I Specific Surface Area, Particle

Diameter, and Dibutyl Phthalate

Absorption Values for Carbon Black

Microadditives Employed

\begin{tabular}{cccc}
\hline Carbon Black & $S\left[\mathrm{~m}^{2} / \mathrm{g}\right]$ & $d[\mathrm{~nm}]$ & $D B P\left[\mathrm{~cm}^{3} / 100 \mathrm{~g}\right]$ \\
\hline XE2 & 620 & 5 & 400 \\
CA & 66 & 49 & 140 \\
\hline
\end{tabular}

based filled polymers in polyethylene-fullerene composites and carbon-fiber-reinforced epoxy and thermoplastic polyimide composites. ${ }^{15,16}$ Results reveal that the addition of carbon-based fillers greatly increases the microhardness of polymeric matrices. Earlier research using indentation tests to learn the mechanical properties of carbon black-polymer composites was mainly concerned with elastomeric matrices systems. ${ }^{17-22} \mathrm{~A}$ few articles reported on the hardness of carbon blacksemicrystalline composites. ${ }^{23,24}$ The influences of carbon black content and type of filler on the hardness of carbon-black-filled isotactic polypropylene and nylon 6 has been reported recently. ${ }^{23,24}$

The present article aims to extend the above studies by reporting on an investigation of the micromechanical properties of carbon black-PC and LDPE composites as revealed by microindentation hardness. The influence of different polymer matrix morphologies and carbon black structures on the microhardness of the various systems is highlighted.

\section{EXPERIMENTAL}

\section{Materials}

Commercial PC and LPDE samples were used as polymer matrices for the preparation of carbon black-polymer composites. PC (bisphenol A) is essentially an amorphous polymer, while LDPE is well known to be a semicrystalline material. The macroscopic density of the LDPE sample employed was $0.92 \mathrm{~g} / \mathrm{cm}^{3} .{ }^{25}$ Two types of microadditives were employed: (1) XE2 Carbon black from Phillips Petroleum (Netherlands), which has a well-developed chainlike structure [dibutyl phthalate absorption $\left.(\mathrm{DBP})=400 \mathrm{~cm}^{3} / 100 \mathrm{~g}\right]$ and (2) acetylene carbon black (CA) from S. E. A. Tudor (Spain), with a less well-developed structure $\left(\mathrm{DBP}=140 \mathrm{~cm}^{3} / 100 \mathrm{~g}\right)$. The specific surface area, $S$; average particle diameter, $d$; ( $d$ is calcu- lated using $d=3225.8 / S)^{1}$; and DBP values for each carbon black type are collected in Table I. Carbon black-polymer composites with different filler contents were prepared using a plastograph as described in references. ${ }^{2,3,25}$ Films $400-700$ $\mu \mathrm{m}$ thick were obtained by melt-pressing the composite samples. ${ }^{2,3}$

\section{Techniques}

Microindentation measurements were performed using a Vickers diamond indenter. Microhardness values were derived from the measurement of the area of the residual impression. A loading cycle of $0.1 \mathrm{~min}$ was used to minimize the creep of the sample under the indenter, and a load of $0.25 \mathrm{~N}$ was applied in all experiments. For further details see reference 12 .

\section{RESULTS AND DISCUSSION}

\section{Carbon Black-PC Composites}

Figure 1 illustrates the plot of the $H$ values versus the carbon black volume concentration, $\phi$, within the polycarbonate samples. Figure 1 also includes, for comparison, the $H$ versus $\phi$ data for a carbon-black-filled ethylene-octene copolymer. ${ }^{20}$ The $H$ values for the carbon-filled ethylene-octene copolymer (24 wt \% of 1-octene

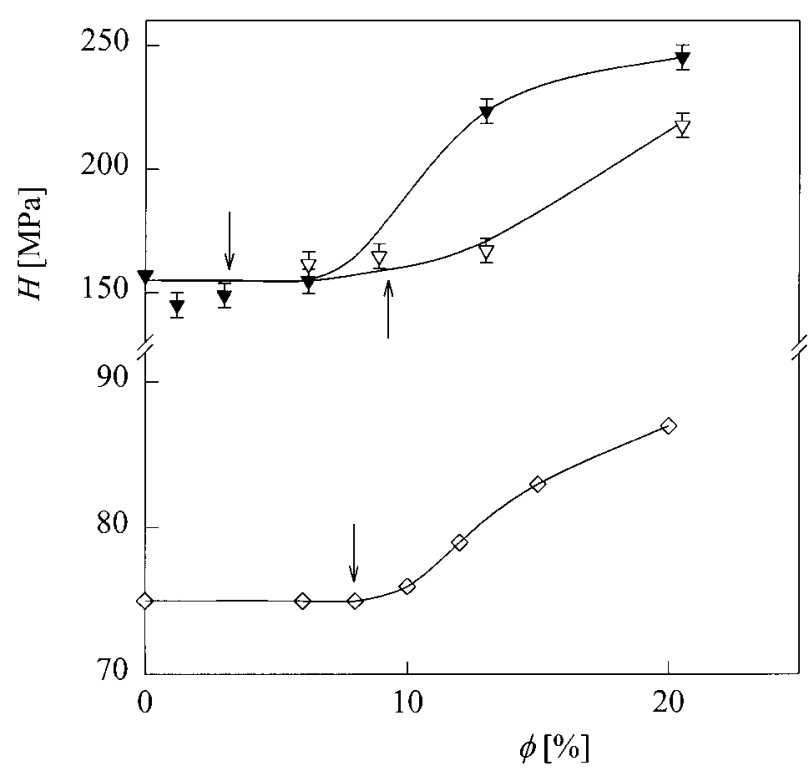

Figure 1 Hardness values of composites versus carbon black content for: $\nabla, \mathrm{XE} 2-\mathrm{PC} ; \nabla, \mathrm{CA}-\mathrm{PC}$; and $\diamond$, carbon black-ethylene octene copolymer. 


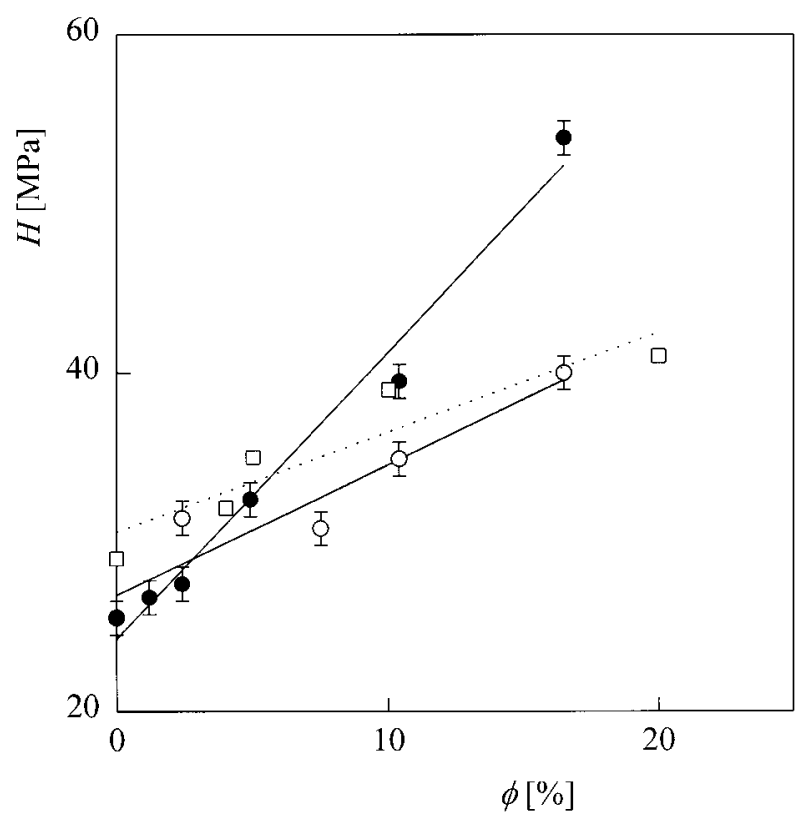

Figure 2 Plot of $H$ versus $\phi$ for composites: 9 , XE2LDPE; $\bigcirc$, CA-LDPE; and $\square$, carbon black-isotactic PP. Solid lines fit to open and solid circles. Dotted line fits to square symbols.

comonomer) were determined using a Shore durometer. Hence, it should be noted that hardness values so derived cannot be correlated with the Vickers microhardness numbers for the carbon black-PC composites reported in the present article. However, we assume that the $H$ variation with $\phi$ for the carbon black-PC and ethyleneoctene copolymer composites can be compared with each other. Figure 1 shows that for low carbon-black-content values $(\phi \leq 6.2 \%)$, the microhardness of carbon black-PC composites is independent of $\phi$ and of the type of carbon black filler. However, at a critical $\phi$ value, $\phi_{H}$, which depends on the type of carbon black, the hardness values of the composites conspicuously increase with a further increase of filler content. The same $H$ behavior with $\phi$ is observed for the carbon-blackfilled ethylene-octene copolymer, the matrix of which is largely amorphous (volume degree of crystallinity, $\alpha=0.10-0.15){ }^{20}$ From Figure 1, $\phi_{H}$ values of $\phi_{H}=6.2 \%$ for the XE2-PC composite and of $\phi_{H}=10-13 \%$ for the CA-PC composite are derived.

\section{Carbon Black-LDPE Composites}

Figure 2 represents the variation of $H$ as a function of carbon black content for the carbon black-
LDPE composites. The $H$ versus $\phi$ data for a carbon-black-filled isotactic polypropylene (iPP) sample in the interval between 0 and $20 \%$ filler content, ${ }^{23}$ are also included for comparison. It should be noted that the hardness value for pure iPP $(H=29 \mathrm{MPa} ; \alpha \approx 0.5)^{23}$ is strikingly low compared to the $H$ values available in the literature for iPP samples with $\alpha \approx 0.5$ ( $H=80-110$ $\mathrm{MPa}){ }^{26,27}$ Moreover, a value of $30 \mathrm{MPa}$ has been reported for the amorphous phase of iPP. ${ }^{26}$ Hardness is well known to be influenced by the time during which the load is held. ${ }^{12}$ We assume that the low $H$ value found for iPP, included in Figure 2 , might be from the use of prolonged indentation times. Unfortunately, Koszkul ${ }^{23}$ does not report the indentation times employed on the iPP hardness measurements.

Figure 2 shows a clear gradual increase of the hardness value of the polymer matrices with increasing carbon black content. In addition, the results reveal that the rate of hardness increase of the carbon black-LDPE composites with volume content of filler depends on the type of carbon black employed. Furthermore, comparison of the data in Figures 1 and 2 reveals that the linear hardness increase as a function of $\phi$ for the carbon black-semicrystalline polymer matrix systems is markedly different from the steplike $H$ behavior with $\phi$ observed for the amorphous polymer matrix composites.

\section{Influence of Filler Structure}

Earlier studies on the electrical conductivity of the carbon black-PC composites currently under investigation showed that the percolation threshold for electrical conductivity for the XE2-PC composite occurs at a lower critical filler concentration $\left(\phi_{c}=3.2 \%\right)$ than that of CA-PC $\left(\phi_{c}\right.$ $=9.3 \%) .{ }^{3}$ This result was explained as a consequence of the different structures of the filler particles within the polymer matrix. Indeed, transmission electron micrographs of XE2-PC and CA-PC composites at $\phi=6.4 \%$ showed a homogenous distribution of aggregates of $60-70 \mathrm{~nm}$ in diameter for the XE2-PC sample, while larger dispersed aggregates, 400-500 $\mathrm{nm}$ in size, were observed for the CA-PC composite. ${ }^{3}$ The smaller interaggregate distance detected on the XE2-PC sample would facilitate electron transfer from one aggregate to another. Hence, a lower XE2 carbon black content is needed to induce the conductivity threshold compared to the CA filler content required for particle percolation. 
Let us next discuss the influence of filler structure on the mechanical properties of the carbon black-PC composites. Figure 1 shows that below a critical value $\phi_{H}$, the hardness values of the carbon black-amorphous matrix composites are insensitive to filler content and particle size. It can be imagined that at low filler concentrations, the carbon black particles dispersed within the amorphous matrix are easily displaced under the indenter. Therefore, filler content and particle size do not influence the mechanical properties of the composite. It is only above a critical concentration, $\phi_{H}$, that the carbon black particles contribute to the material resistance to plastic deformation. Figure 1 reveals that the $\phi_{H}$ value required for mechanical enhancement of the amorphous polymeric matrix is lower for smallersized carbon black particles (XE2). Electron micrographs reveal a finer aggregate size of XE2 filler particles within the polycarbonate matrix in relation to the coarse aggregates observed on the CA-PC composite. ${ }^{3}$ The lower $\phi_{H}$ value found for the XE2-PC sample compared to that found for the CA-filled composite could be attributed to the more homogeneously dispersed fine aggregates observed on the former composite. This well-developed structure would harden the material more effectively than the larger dispersed aggregates present on the CA-PC composites.

Finally, it is worth pointing out that in all cases, $\phi_{H}>\phi_{c}$ (arrows in Fig. 1 indicate the $\phi_{c}$ value for each material). This result indicates that the microhardness of the composites is less sensitive to filler content than the electrical conductivity is.

\section{Influence of Matrix Morphology}

Preceding studies showed that when carbon black is added to a semicrystalline matrix, the $\phi_{c}$ value is lower than the percolation threshold for an amorphous matrix-carbon black composite of the same filler $\left[\phi_{c}(\mathrm{XE} 2-\mathrm{LDPE})=1 \%, \phi_{c}(\mathrm{XE} 2-\mathrm{PC})\right.$ $=3.2 \%, \phi_{c}(\mathrm{CA}-\mathrm{LDPE})=8.5 \%, \phi_{c}(\mathrm{CA}-\mathrm{PC})$ $=9.3 \%] .^{2,3,25}$ This is so because the crystalline domains within the semicrystalline matrix tend to confine the carbon particles in the amorphous domains, facilitating their contact. ${ }^{20}$

The different $H$ behavior observed for the carbon black-semicrystalline and amorphous matrix composites shown in Figures 1 and 2 could be explained in a similar manner in terms of the different distributions of the filler particles within the polymer matrix. Figure 2 shows that for car-

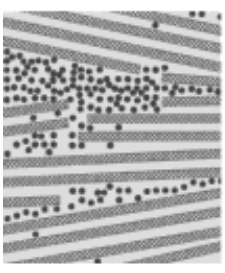

(a)

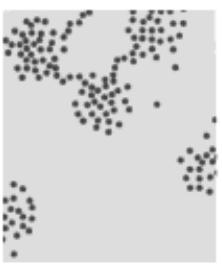

(b)

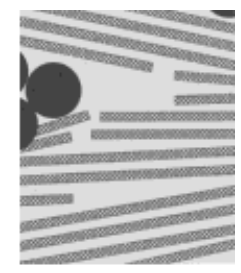

(c)
Figure 3 Schematics of the morphology for carbon black-polymer composites: (a) XE2-LDPE; (b) XE2PC; and (c) CA-LDPE.

bon-filled semicrystalline polymer composites, the carbon black reinforcing effect already is significant at very low carbon black concentrations. Indeed, this is at variance with what is observed in the case of the amorphous polymer composites, where $H$ is shown to be insensitive to filler content below a critical value $\phi_{H}$ (Fig. 1). While the filler particles within the semicrystalline matrix composites are selectively rejected into the amorphous regions between crystal lamellae, in the case of the amorphous matrix composites, the microadditive is dispersed without any restriction within the polymeric matrix. In the former semicrystalline composites, compression of the confined filler particles between LDPE lamellae significantly increases the resistance to plastic deformation, even at a low carbon black content. In the latter composites, however, the dispersed aggregates within the amorphous matrix are easily displaced under the indenter at low filler concentrations. In order to better visualize the above arguments, in Figure 3 we attempt to describe the most representative features of the morphologies of the semicrystalline and amorphous composites. Figure 3(a) illustrates the channels of carbon black particles (solid circles) constrained between crystal lamellae, while in Figure 3(b) the filler particles are distributed at random within the amorphous matrix. In Figure 3(c) the large size of the carbon black aggregate imposes a larger filler concentration at given points within the lamellar material. It is convenient to stress that the models in Figure 3 are only intended to be a schematic representation in order to explain qualitatively the microhardness results. Further electron microscopy studies will be necessary to provide more accurate morphological details.

Figure 2 also shows that the hardness values of the XE2-LDPE composite increase at a higher rate with increasing $\phi$ than do the $H$ values of the CA-LDPE composite. This result can be associ- 
ated with the smaller size of the XE2 carbon black particles. It is noteworthy that the rate of hardness increase with increasing $\phi$ value for the carbon-filled PP composite $(d=25 \mathrm{~nm})$ is closer to the rate of $H$ increase of the CA-LDPE composite $(d=49 \mathrm{~nm})$ than to that of the XE2-LDPE material $(d=5 \mathrm{~nm})$. In the case of the CA-LDPE composite, it can be expected that the less homogeneous distribution of the volume occupied by the large filler particles would induce a less efficient hardening of the material [Fig. 3(c)].

\section{Hardening of Amorphous Layers in the Semicrystalline Polymer}

In previous studies we have shown that the inclusion of inorganic atoms in the interlamellar layers induces a hardening of the amorphous phase. ${ }^{28}$ The hardness increase with increasing filler content detected for carbon black-LDPE composites could be similarly related to the hardness enhancement of the amorphous regions from the incorporation of filler particles. The average hardness value of the amorphous interlamellar regions of the carbon-black-reinforced LDPE can be estimated on the basis of the hardness-additivity relationship ${ }^{12}$ :

$$
H=H_{c} \alpha+H_{a}(1-\alpha)
$$

where $H_{c}$ and $H_{a}$ are the hardness of the crystalline and amorphous regions, respectively, and $\alpha$ is the volume fraction of the crystalline material. Eq. (1) describes the hardness of a semicrystalline material in terms of a parallel model of alternating crystalline and amorphous layers. ${ }^{12}$ Let us assume now that when carbon particles are incorporated in the amorphous regions, $H_{a}$ can be described using

$$
H_{a}=H^{C B} \phi^{\prime}+H_{a}^{L D P E}\left(1-\phi^{\prime}\right)
$$

where $H^{C B}$ and $H_{a}^{L D P E}$ are the hardness of the carbon black particles and the amorphous regions of the LDPE matrix, respectively, and $\phi^{\prime}$ is the volume fraction of carbon black within the amorphous layers. The value of $\phi^{\prime}$ in eq. (2) is related to $\phi$ through: $\phi^{\prime}=0.01 \phi /(1-\alpha)$ and $H_{a}^{L D P E}$ $\approx 0 .{ }^{29}$

The hardness of the amorphous regions of LDPE containing carbon black, $H_{a}$, can be derived from eq. (1) using the value of $\alpha=0.5$, as derived from density, ${ }^{25}$ together with the hardness values of the composites from Figure 2 (open

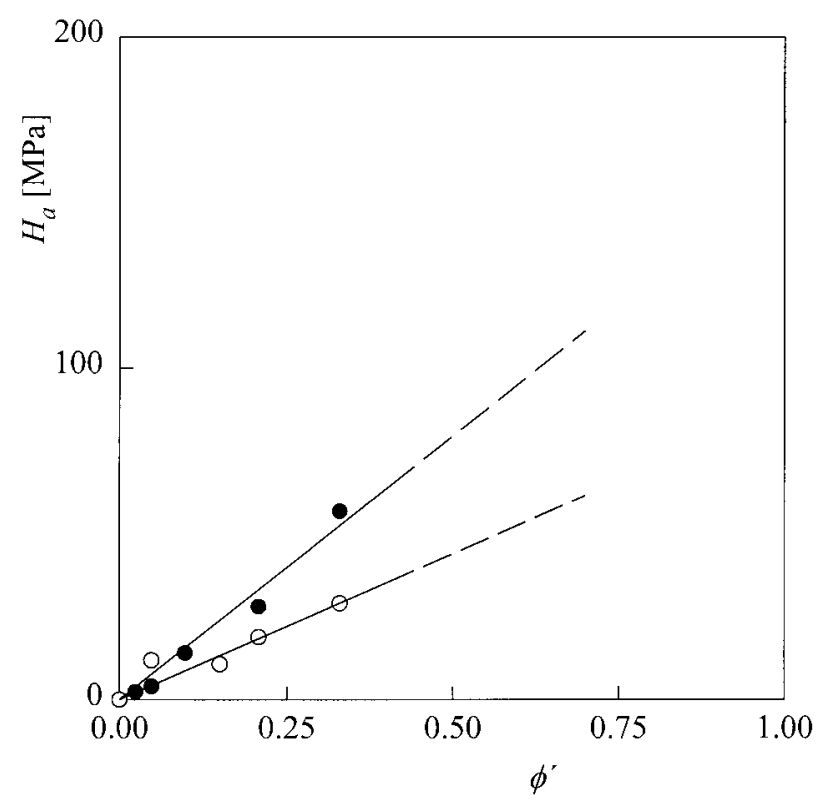

Figure 4 Hardness value of the amorphous interlamellar regions as a function of filler concentration within the amorphous layers (see text) for: $\bullet$, XE2LDPE; O, CA-LDPE.

and solid circles). Figure 4 shows the plot of the $H_{a}$ values of the carbon black-LDPE composites versus $\phi^{\prime}$. A straight line following eq. (2) is fitted to each composite. Figure 4 shows the remarkable influence of filler particles on the microhardness of the amorphous regions. For example, the inclusion of filler particles for $\phi^{\prime}=0.40$ (20\% of carbon black volume content within the composite) induces a large hardening of the amorphous regions, from $H_{a}=0 \mathrm{MPa}$ up to $H_{a}=35 \mathrm{MPa}$ and $H_{a}=64 \mathrm{MPa}$ for the CA and XE2 carbon black aggregates, respectively. Extrapolation of the straight lines in Figure 4 to high $\phi^{\prime}$ values should be done with caution, as the steric hindrance between the LDPE molecules and the carbon black particles would prevent large concentrations of filler being incorporated into the amorphous regions.

\section{CONCLUSIONS}

(1) Below a critical filler content value, $\phi_{H}$, the microhardness of carbon black-amorphous matrix (PC) composites is independent of the volume concentration of carbon black $\phi$, while above $\phi_{H}, H$ conspicuously increases with increasing $\phi$.

(2) The microhardness of carbon black-semi- 
crystalline matrix (LDPE) composites increases linearly with increasing filler content.

(3) The different $H$ behaviors found for PC and LDPE matrices with the addition of carbon black is attributed to the particle distribution within the polymeric matrix.

(4) It is suggested that when carbon particles are added to a semicrystalline matrix, the filler aggregates tend to be predominantly confined between crystalline lamellae. However, when the microadditive is mixed with the amorphous polymer, the carbon black particles are dispersed at random within the amorphous matrix.

(5) The well-developed structure of the XE2 carbon black (smaller particle and aggregate size) with respect to the CA carbon black is shown to harden both the PC and LDPE matrices more effectively.

A.F. thanks the Comunidad Autónoma de Madrid for the award of a postdoctoral grant.

\section{REFERENCES}

1. Sichel, E. K. Carbon Black-Polymer Composites; Marcel Dekker, Inc.: New York, 1982.

2. Ezquerra, T. A.; Baltá Calleja, F. J.; Plans, J. J Mater Res 1986, 1, 510.

3. Ezquerra, T. A.; Martínez Salazar, J.; Baltá Calleja, F. J. J Mater Sci Lett 1986, 5, 1065.

4. Bayer, R. K.; Ezquerra, T. A.; Zachmann, H. G.; Baltá Calleja, F. J.; Martínez Salazar, J.; Meins, W.; Diekow, R. E.; Wiegel, P. J Mater Sci 1988, 23, 475.

5. Ezquerra, T. A.; Bayer, R. K.; Baltá Calleja, F. J. J Mater Sci 1988, 23, 4121.

6. Savage, G. Carbon-Carbon Composites; Chapman \& Hall: London, 1993.

7. Pérez, E.; Pereña, J. M.; Benavente, R.; Bello, A.; Lorenzo, V. Polym Bulletin 1992, 29, 233.
8. Gündüz, G.; Kirkin, M. Polymer International 1994, 35, 61.

9. Briscoe, B. J.; Sebastian, K. S.; Sinha, S. K. Phil Mag A 1996, 74, 1159.

10. Baltá Calleja, F. J.; Fakirov, S. Trends Polym Sci 1997, 5, 246.

11. Deslandes, Y.; Alva Rosa, E.; Brisse, F.; Meneghini, T. J Mater Sci 1991, 26, 2769.

12. Baltá Calleja, F. J. Trends Polym Sci 1994, 2, 419.

13. Baltá Calleja, F. J.; Giri, L.; Ward, I. M.; Cansfield, D. L. M. J Mater Sci 1995, 30, 1139.

14. Flores, A.; Baltá Calleja, F. J.; Attenburrow, G. E.; Bassett, D. C. Polymer 2000, 41, 5431.

15. Baltá Calleja, F. J.; Giri, L.; Asano, T.; Mieno, T.; Sakurai, A.; Ohnuma, M.; Sawatari, C. J Mater Sci 1996, 31, 5153.

16. Paplham, W. P.; Seferis, J. C.; Baltá Calleja, F. J.; Zachmann, H. G. Polym Composites 1995, 16, 424.

17. Dutta, N. K.; Tripathy, D. K. J Appl Polym Sci 1992, 44, 1635.

18. Khaled, M. A.; Hassan, E. A.; Elwy, A.; Metwally, E. E. Mater Lett 1994, 19, 325.

19. Debnath, S. C.; Mandal, S. K.; Basu, D. K. J Appl Polym Sci 1995, 57, 555.

20. Huang, J. C.; Huang, H. L. J Polym Engng 1997, $17,213$.

21. Hamza, S. S. Polym Testing 1998, 17, 131.

22. Huang, J. C.; Chuang, S. F.; Su, T. Y.; Grossman, S. J. J Polym Engng 1999, 19, 39.

23. Koszkul, J. J Polym Engng 1998, 18, 249.

24. Pinto, G.; López González, C.; Jiménez Martín, A. Polym Composites 1999, 20, 804.

25. Ezquerra, T. A. Ph.D. Thesis, Universidad Complutense de Madrid, 1986.

26. Baltá Calleja, F. J.; Martínez Salazar, J.; Asano, T. J Mater Sci Lett 1988, 7, 165.

27. Flores, A.; Aurrekoetxea, J.; Gensler, R.; Kausch, H. H.; Baltá Calleja, F. J. Colloid Polym Sci 1998, 276, 786 .

28. Baltá Calleja, F. J.; Giri, L.; Michler, G. H.; Naumann, I. Polymer 1997, 38, 5769.

29. Baltá Calleja, F. J.; Kilian, H. G. Colloid Polym Sci 1988, 266, 29. 